Modelling economic response to harvest and effort control in North Sea cod fishery

Hoff, Ayoe Gry; Frost, Hans Staby

Published in:

Aquatic Living Resources

DOI:

10.1051/alr:2008038

Publication date:

2008

Document version

Publisher's PDF, also known as Version of record

Citation for published version (APA):

Hoff, A. G., \& Frost, H. S. (2008). Modelling economic response to harvest and effort control in North Sea cod fishery. Aquatic Living Resources, 21(3), 259-264. https://doi.org/10.1051/alr:2008038 


\title{
Modelling economic response to harvest and effort control in North Sea cod fishery
}

\author{
Ayoe Hoff ${ }^{\mathrm{a}}$ and Hans Frost \\ Institute of Food and Resource Economics, Faculty of Life Science, University of Copenhagen, Rolighedsvej 25, \\ 1958 Frederiksberg C, Denmark
}

Received 13 September 2007; Accepted 13 March 2008

\begin{abstract}
A number of European fishing fleets have been regulated through a combination of quota and effort (sea days) controls since 2004. These two regulation schemes are, however, interrelated, i.e. a given quota limit will necessarily determine the effort used and vice versa. A bioeconomic feedback model is presented which takes this causality between effort and harvest control into account, and switches back and forth between these two regulation schemes depending on which is the binding rule. The model is based on biological stock projection, and quotas are set using the Pope approximation while an economic production function is used to estimate the harvest when the effort is binding. The economic response of the fleet is modelled through a dynamic investment/disinvestment module which evaluates the change in the fleet capacity given the economic outcome of the fishery. A simple example is presented for the Danish seiners catching cod in the North Sea. The model has been constructed as part of the 6th framework project "Operational Evaluation Tools for Fisheries Management Options (EFIMAS)".
\end{abstract}

Key words: Combined quota and effort control / Bio-economic modelling / FLR (Fisheries Laboratory in language R)

\section{Introduction}

With the introduction of the 2002 reform (EC 2002) of the Common Fishery Policy (CFP) for EU waters, effort control was introduced alongside quota control and limited entry to the fishery in form of capacity restrictions (fishing licenses). The reasons to include effort control parallel to quotas are (i) considering the large overcapacity of the European fishing fleet quotas do not seem adequate to limit the actual amount of fish being caught, and (ii) the multi-species nature of most fisheries often results in over-exploitation and subsequent discarding of some species, which may to some degree be avoided by effort control.

The assumption that harvest and effort are interrelated is implicit in the introduction of effort-regulation, i.e. a given observed harvest will necessarily determine the effort used, and correspondingly, a given effort will determine the harvest. Thus, given the combined quota and effort regulation, one of the two will always be the limiting factor which determines the actual harvest.

It is therefore important to acknowledge the issue of causality between regulation methods when modelling the effects of a given management scheme. This paper presents a bio-economic simulation model developed with the aim to assess the economic as well as the biological effects of recovery plans including effort control, taking the causal relationship

\footnotetext{
a Corresponding author: ah@foi.dk
}

between the quota restrictions and the additional sea day limitations into account. The model is thus able to switch between harvest and effort control of the fishery. This switching mechanism is an improvement of existing bio-economic models which usually consider either harvest or effort control. As such, the model presented in this paper opens up for more realistic and complete assessments of the new CFP. The model is based on previous work (Hoff and Frost 2006) where a bio-economic model for dynamic fleet capacity change was developed in connection with the 6th framework programme EFIMAS (Operational Evaluation Tools for Fisheries Management Options, EFIMAS 2007).

As an example the model uses Danish seiners catching cod in the North Sea as a specific case study employing the recovery scheme for the North Sea cod set by the European Commission in 2004 (EC 2004). It is well-known that the cod stock in the North Sea has been steadily decreasing since the early 1970 s, and it is at present at the lowest observed level over the last century (ICES 2005). The cod spawning stock biomass $(S S B)$ should be at least $S S B_{\text {lim }}=70000 \mathrm{t}$ in order to reproduce itself, and observing that the biomass was $\sim 50000 \mathrm{t}$ in 2005 it is clear that the stock may suffer from reduced reproductive capacity. In 2004, the European Commission thus introduced a specific recovery plan for the North Sea Cod (EC 2004) in which the harvest and effort control rules were formulated with the aim to increase the stock to above the precautionary level of $S S B_{\mathrm{Pa}}=150000 \mathrm{t}$. The harvest rule states that the catch in 
a given year must be set at a level which allows the $S S B$ of cod to increase by at least $30 \%$ relative to the previous year until the precautionary level is reached. Moreover, the fishing mortality rate must not exceed 0.65 . These aims are enforced through combined TAC and effort regulation, the latter stating that seine vessels must not have more than 22 active fishing days in the North Sea per month.

A large part (37 out of a total of 62 vessels in 2003) of the Danish seine fleet operates in the North Sea at a full- or parttime basis. The Danish seiners generally target cod and plaice, and the landings value of cod for this fleet segment constituted on average $\sim 25 \%$ of the total landings value for this segment in the period 2002-2004. The Danish seiners take $\sim 10 \%$ of the total Danish cod landings from the North Sea, while the Danish share of cod in the North Sea constitutes $20 \%$ of the North Sea TAC for the European Union. Thus, the Danish seiners take $\sim 2 \%$ of the EU TAC of cod in the North Sea. As such the Danish seine fleet will not have any significant influence on the state of the cod stock in the North Sea. The reduction of cod quotas resulting from the recovery programme discussed above may, however, have a significant influence on the economy of the Danish seiners fishing in the North Sea.

\section{Methods}

The model includes a biological and an economic operation module, the former simulating the stock assessment and establishment of quotas each year, and the latter simulating the economic dynamics of the fleet, i.e. fleet catches and earnings, fleet effort and investment/disinvestment in capital.

The model is generally an improvement of existing bioeconomic models (see e.g., Skjold et al. 1996; Danielsson et al. 1997; Garza-Gil et al. 2003, 2006; Da-Rocha and Gutiérrez $2004,2006)$ in the sense that it is possible to take parallel quota and effort regulation into account. In this respect, the model is an important contribution to the ongoing work of assessing existing and proposed management schemes. As such, it should be kept in mind that although the model presented below focuses on evaluating the effect on one fleet of the cod recovery programme in the North Sea, it can easily be applied to other scenarios.

The model is initiated in each year $y(y>1)$ of the simulation period by evaluating the number of vessels $N V_{F l}^{y}$ (capacity) in the fleet ${ }^{1} F l$ at the start of year $y$, based on previous years total profit (of all species being caught by the fleet):

$N V_{F l}^{y}=N V_{F l}^{y-1}+\Delta N V_{F l}^{y} \quad$ when $\quad N V_{F l}^{\mathrm{MIN}} \leqslant N V_{F l}^{y} \leqslant N V_{F l}^{\mathrm{MAX}}$.

Where

$$
\begin{aligned}
\Delta N V_{F l}^{y}= & \begin{cases}\frac{I_{F l}^{+} \cdot \Pi_{F l}^{y}}{V_{F l}^{\mathrm{In}}} ; \quad \Pi_{F l}^{y} \geqslant 0 \\
\frac{I_{F l}^{-} \cdot \Pi_{F l}^{y}}{V_{F l}^{\text {Out }} ;} \Pi_{F l}^{y}<0 ;\end{cases} \\
\Pi_{F l}^{y}= & \frac{\left(1-(1+r)^{L T}\right)}{r} \cdot\left(\frac{1}{1+L G T_{F l}} \sum_{i=0}^{L G T_{F l}} P_{F l}^{(y-1)-L A G_{F l}-i}\right)
\end{aligned}
$$

\footnotetext{
${ }^{1}$ In the present case the "fleet" specifies that part of the Danish seine fleet that operates specifically in the North Sea.
}

$N V_{F l}^{\mathrm{MAX}}$ and $N V_{F l}^{\mathrm{MIN}}$ are the maximum and minimum number of vessels allowed in the fleet. $\Pi_{F l}^{y}$ is the average discounted (total) profit over $L G T$ years for fleet $F l$, used for evaluating capacity change. $V_{F l}^{\mathrm{In}}$ and $V_{F l}^{\text {Out }}$ are the prices per unit capacity of investment/disinvestment. $I_{F l}^{+}$and $I_{F l}^{-}$reflect partial adjustment, i.e. the shares of positive respectively negative profits used for investment/disinvestment in the capacity. $L A G_{F l}$ is the lag in investment decision, i.e. the number of years it takes from decision to invest/disinvest until the change is actually put into force. $P_{F l}^{y}$ is the net total profit taken by fleet segment $F l$ in year $y$. Finally $r$ is the interest rate and $L T$ the expected lifetime of a vessel. It is at present assumed that there is no decommissioning.

In principle, the investment/disinvestment exit function given in equation (1) is based on future expectation, but because of lack of information, past evidence in terms of profit is used. It is assumed that the change in capacity is determined by the opportunity cost of capital including an option for asymmetry in entry and exit. The price of a vessel $V_{F l}^{\text {In }}$ transforms pecuniary capital into physical capital, and the reciprocal of $V_{F l}^{\text {Out }}$ includes the fishermans perception of opportunity costs (see also Bjørndal and Conrad 1987).

The next step is to determine the stock of the target species (in the present case cod) at the beginning of year $y$, and set the total allowable catch (TAC) of the species for this year. In the present context, the stock at the beginning of each year is set by the Pope approximation to cohort analysis (Sparre 1998):

$$
N_{a}^{y}=N_{a-1}^{y-1} \cdot \exp \left(-m_{a-1}\right)-C_{a-1}^{y-1} \cdot \exp \left(-m_{a-1} / 2\right) ; \quad y>1
$$

$N_{a}^{y}$ is the number of cod in the stock at age $a$ in year $y . C_{a-1}^{y-1}$ is the number of cod caught in year $y-1$ at age $a-1$. $m_{a-1}$ is the natural mortality of the stock at age $a-1$. The number of recruits $N_{1}^{y}$ is set by the Ricker stock recruitment relationship based on historical stock and recruitment numbers dating back to 1963 (ICES, 2006). It has been chosen to use the Pope approximation rather than the more correct cohort equation $N^{y}=N^{y-1} \cdot \exp (-(M+F))$, as the Pope equation has also been used to set the TAC in year $y$. By using this approach, instead of the cohort formula, the quotas are set directly without the need to estimate the fishing mortality rate.

While the cod SSB is below the precautionary level $S S B_{\mathrm{Pa}}=150000 \mathrm{t}$, the cod quota in year $y$ is set according to the harvest rules stated above, i.e. the spawning stock biomass of cod must increase by at least $30 \%$ each year until the precautionary level is reached. I.e. $S S B^{y} \geqslant 1.3 \cdot S S B^{y-1}$ with $S S B^{y}=$ $\sum_{a} N_{a}^{y} \cdot w_{a}$. mat $_{a}$, where $w_{a}$ and mat $_{a}$ are the weight and fraction of mature individuals at age $a$ of the stock. Thus, the management rule states that $\sum_{a} N_{a}^{y} \cdot w_{a} \cdot$ mat $_{a} \geqslant 1.3 \cdot \sum_{a} N_{a}^{y-1} \cdot w_{a}$. $m a t_{a}$. Seeing that $m a t_{1} \sim 0$ for cod, this rule is approximately fulfilled if $N_{a}^{y} \geqslant 1.3 \cdot N_{a}^{y-1}$ for $a>1$. Using the Pope formula (Eq. (2)) and rearranging, the TAC in year $y$ must fulfil:

$$
\operatorname{tac}_{a}^{y} \leqslant N_{a}^{y} \cdot \exp \left(-m_{a} / 2\right)-1.3 \cdot N_{a+1}^{y} \cdot \exp \left(m_{a} / 2\right) ; \quad a \geqslant 1 .
$$

In the present model, $\operatorname{tac}_{a}^{y}$ has been set equal to the above expression when this is greater than zero, while $\operatorname{tac}_{a}^{y}=0$ otherwise. The latter case then indicates a ban of fishing cod at certain ages, usually the young fish. Notice that $\operatorname{tac}_{a}^{y}$ is defined as the total allowable catch of cod at age $a$ measured in number 
of cod. It is of course unrealistic to enforce age disaggregated TACs for real, but $t a c_{a}^{y}$ is included for modelling purposes. At the same time, this illustrates that it may be forbidden to harvest cod at certain ages

When the cod SSB is higher than $S S B_{\mathrm{Pa}}$ it is assumed that the aim is to keep $S S B^{y}=S S B_{\mathrm{Pa}}$. Using the above argumentation, the TAC is then set equal to:

$$
\operatorname{tac}_{a}^{y}=N_{a}^{y} \cdot \exp \left(-m_{a} / 2\right)-N_{a+1}^{y} \cdot \exp \left(m_{a} / 2\right) ; \quad a \geqslant 1 .
$$

The total allowable catch $(T A C)$ measured in weight of cod in the North Sea in year $y$ is then given by:

$$
T A C^{y}=\sum_{a} t a c_{a}^{y} \cdot w_{a}
$$

If all fleets sharing this $T A C$ are able to take their full quotas this will be equal to the catch of North Sea cod in year $y$, but given the additional effort restriction, the fleets may not be able to take their full quotas, thus decreasing the actual total cod catch in year $y$.

The quota for the Danish seine fleet operating in the North Sea is given by:

$Q_{F l}^{y}=F S S_{F l} \cdot C S \cdot T A C^{y} \equiv \sum_{a} q_{F l, a}^{y}=\sum_{a} F S S_{F l} \cdot C S \cdot t a c_{a}^{y} \cdot w_{a}$

$C S$ is the country share ${ }^{2}$ of the total cod TAC, and $F S S_{F l}$ is the fleet segment share of the country quota. Both are assumed constant in the present context. $q_{F l, a}^{y}$ is defined as the quota of cod at age $a$ for the fleet (measured in weight), and like $\operatorname{tac}_{a}^{y}$ it is included for modelling purposes. $Q_{F l}^{y}$ will be the amount of cod harvested by the fleet in year $y$, given that the necessary effort (number of sea days per vessel) $E q_{F l}^{y}$ to take this quota will not exceed the effort limit $E \max _{F l}^{y}$ included in the recovery scheme. $E q_{F l}^{y}$ is estimated by:

$$
E q_{F l}^{y}=\frac{Q_{F l}^{y}}{N V_{F l}^{y} \cdot Q P U E_{F l}^{y}}
$$

$Q P U E_{F l}^{y}$ is the (quota) catch of cod per unit effort (i.e. per fishing day) and is given by:

$$
\begin{aligned}
Q P U E_{F l}^{y} & =\text { cpue }_{F l}^{1} \cdot\left(\frac{S B^{y}}{S B^{1}}\right)^{\beta_{F l}} \cdot\left(\frac{Q_{F l}^{y}}{Q_{F l}^{1}}\right)^{-\gamma_{F l}} ; \quad \beta_{F l}, \gamma_{F l} \geqslant 0 \\
\text { cpue }_{F l}^{1} & =\frac{H_{F l}^{1}}{N V_{F l}^{1} \cdot E_{F l}^{1}}
\end{aligned}
$$

$N V_{F l}^{1}$ and $E_{F l}^{1}$ are the observed number of vessels and the observed effort (number of days at sea) used on the average per vessel in fleet segment $F l$ in the start year. $c p u e_{F l}^{1}$ and $H_{F l}^{1}$ are the catch per unit effort and total harvest of cod (measured in weight) for the Danish seine fleet in the start year. $S B^{y}$ is the stock biomass in year $y$ given by $\sum_{a} N_{a}^{y} \cdot w_{a}$. The QPUE relationship is a result of assuming that landings are determined by the conventional economic Cobb-Douglas production function (see also Hoff and Frost 2008). The Cobb-Douglas function is, among others, also applied for the harvest of cod in the

\footnotetext{
2 Also called the relative stability.
}

North Sea by Eide et al. (2003). Notice that the quota catch per unit effort increases with the stock, but decreases with the quota. The latter is based on the assumption that the production relationship between catch and effort displays non-increasing returns to scale.

The effort evaluated by equation (7) may, however, exceed the effort limit $\operatorname{Emax}_{F l}^{y}$ set by the recovery plan, and it will thus not be possible for the fleet to harvest its total quota. If $E q_{F l}^{y}>E \max _{\mathrm{Fl}}^{\mathrm{y}}$, the actual harvest of cod for the fleet segment is estimated by scaling down the quota:

$$
h_{F l}^{y, a}=q_{F l, a}^{y} \cdot\left(\frac{\operatorname{Emax}_{\mathrm{Fl}}^{\mathrm{y}}}{E q_{\mathrm{Fl}}^{\mathrm{y}}}\right)^{\frac{1}{1+\gamma_{F l}}}
$$

$h_{F l}^{y, a}$ is the actual harvest (measured in weight) of cod at age $a$ taken by the fleet in year $y$. The scaling used in equation (9) is derived using the QPUE relationship given in equation (8) and demanding (i) that the number of vessels stays constant, and (ii) that the observed effort used by the fleet in year $y$ will be equal to $\operatorname{Emax}_{F l}^{y}$. The total harvest of cod in year $y$ is $H_{F l}^{y}=$ $\sum_{a} h_{F l}^{y, a}$.

Finally, if the fleet is not able to catch its total quota the cod TAC will not be fully exploited, and the actual catches (measured in numbers) of cod in year $y$ will then $b^{3}$ :

$$
C_{a}^{y}=\operatorname{tac}_{a}^{y}-\frac{q_{F l, a}^{y}}{w_{a}}+\frac{h_{F l}^{y, a}}{w_{a}} .
$$

The total landings value (including all species caught) $R_{F l}^{y}$ of the fleet segment in year $y$ is given by:

$R_{F l}^{y}=\frac{1}{C V F_{F l} \cdot C C F_{F l}} \sum_{a} p_{a}^{y} \cdot h_{F l}^{y, a} ; \quad p_{a}^{y}=p_{a}^{1} \cdot\left(\frac{T A C^{y}}{T A C^{1}}\right)^{\alpha} \quad \alpha \leqslant 0$

$C C F_{F l}$ is the fraction which the cod harvested in the North Sea constitutes of the total cod catch for the Danish seine fleet. $C V F_{F l}$ is the fraction which the total catch value of cod (for all fishing grounds) constitutes of the total catch value for the Danish seine fleet. Scaling the earnings from the cod catch in the North Sea by these two factors ensures that $R_{F l}^{y}$ estimates the total revenue of the fleet for all species caught in all operating areas.

The variable costs $V C_{F l}^{y}$ and fixed costs $F C_{F l}^{y}$ are given by:

$$
\begin{gathered}
V C_{F l}^{y}=V C_{F l}^{1} \cdot\left(\frac{E_{F L}^{y} \cdot N V_{F l}^{y}}{E_{F L}^{1} \cdot N V_{F l}^{1}}\right) \\
F C_{F l}^{y}=F C_{F l}^{1} \cdot\left(\frac{N V_{F l}^{y}}{N V_{F l}^{1}}\right) .
\end{gathered}
$$

I.e. the variable costs are scaled by the effort relative to the variable costs in year 1 , and the fixed costs are scaled by the capacity. The effort $E_{F L}^{y}$ used in equation (12) is the actual effort applied by the fleet in year $y$, i.e. $E q_{F l}^{y}$ or $E m a x_{F l}^{y}$ depending on which is the minor of the two. Finally, the total profit taken by the fleet in year $y$ is given by:

$$
P_{F l}^{y}=R_{F l}^{y}-V C_{F l}^{y}-F C_{F l}^{y} .
$$

\footnotetext{
3 Assuming that the part of the quota taken by other vessel groups will be fully exploited.
} 


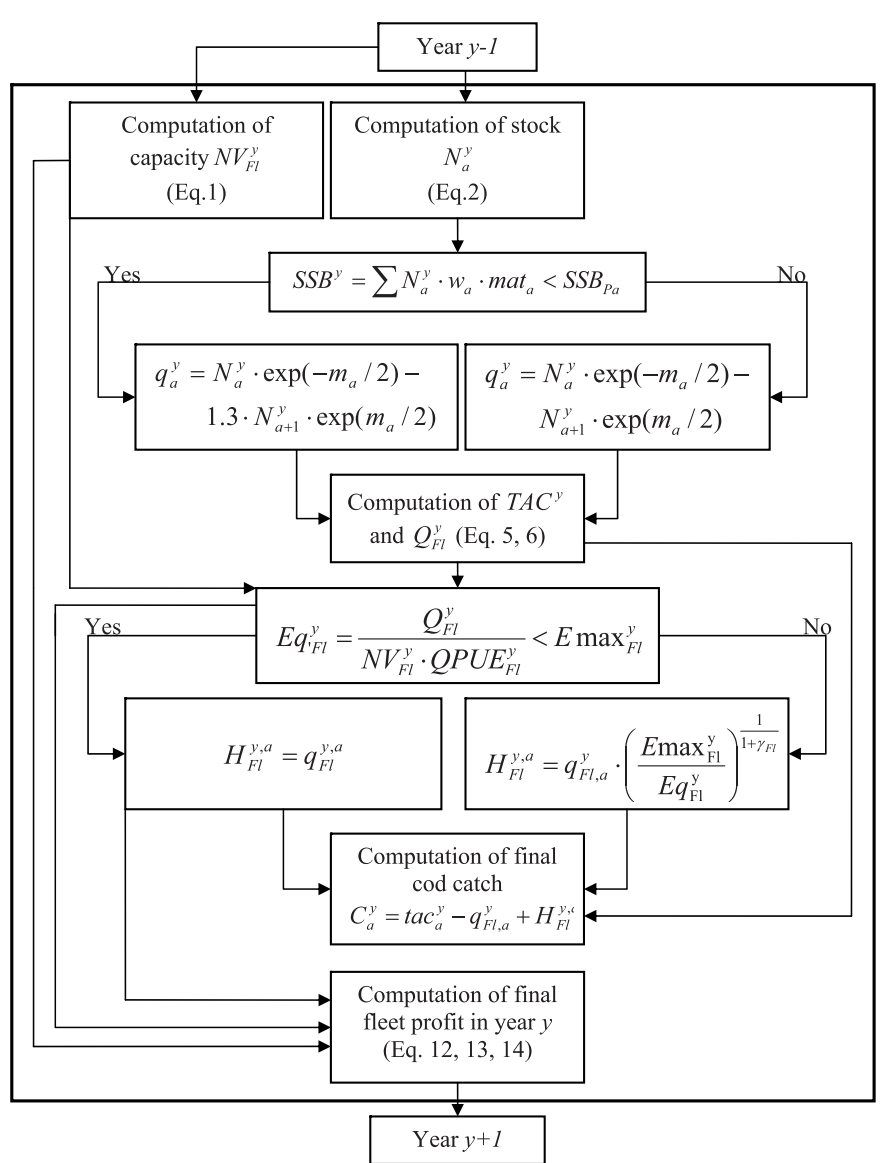

Fig. 1. Chart of the algorithm used to carry out the FLR simulation.

This brings the model back to the start, as this profit is used in the subsequent years to assess the change of fleet capacity (Eq. (1)) which, as it is seen by the above model, is strongly dependent on the fleet harvest, and thus on the current management scheme.

\subsection{Model implementation}

The model described above has been implemented in FLR (Fisheries Laboratory in $R$, Kell et al. 2007), which is a "collection of tools in $\mathrm{R}$ that facilitates the construction of bio-economic simulation models of fisheries and ecological systems" (FLR 2007). FLR has been developed under the 6th framework programme EFIMAS (Operational Evaluation Tools for Fisheries Management Options, EFIMAS 2007). R is a freeware/shareware system for statistical computation and graphics.

The simulation model runs over 10 years using a loop which feeds results from previous years into the computations for the year in question. As indicated above, the model meets several branches during each yearly computation which leads the model in different directions. One branch is e.g. the test whether the effort needed to take the quota (Eq. (7)) is less than the maximum effort set by the management scheme. Figure 1 gives a graphical illustration of the algorithm used to carry out the simulation in FLR.
Table 1. Initialisation data $($ year $=2003$ ) for the cod stock in the North Sea. Source: ICES (2006).

\begin{tabular}{cccccc}
\hline Age & $\begin{array}{c}\text { Stock } \\
\text { numbers at } \\
\text { age } \\
\text { (thousands) }\end{array}$ & $\begin{array}{c}\text { Catch } \\
\text { numbers at } \\
\text { age } \\
\text { (thousands) }\end{array}$ & $\begin{array}{c}\text { Natural } \\
\text { mortality }\end{array}$ & Maturity & $\begin{array}{c}\text { Catch } \\
\text { weight at } \\
\text { age (kg) }\end{array}$ \\
\hline 1 & 89142 & 8911 & 0.8 & 0.01 & 0.275 \\
2 & 69782 & 19591 & 0.35 & 0.05 & 0.752 \\
3 & 17433 & 4621 & 0.25 & 0.23 & 1.533 \\
4 & 9899 & 2729 & 0.2 & 0.62 & 3.191 \\
5 & 1538 & 460 & 0.2 & 0.86 & 5.113 \\
6 & 241 & 68 & 0.2 & 1 & 7.27 \\
$7+$ & 261 & 50 & 0.2 & 1 & 11.076 \\
\hline
\end{tabular}

Table 2. Initialisation data (year $=2003$ ) for the fleet of Danish seiners operating in the North Sea.

\begin{tabular}{ll}
\hline Parameter & Value \\
\hline Number of vessels $\left(N V_{F l}^{1}\right)$ & 37 \\
Fishing days per vessel $\left(E_{F l}^{1}\right)$ & 171 \\
Variable cost for the total fleet $\left(V C_{F l}^{1}\right)$ & $8415 \times 10^{3} €$ \\
Fixed cost for the total fleet $\left(F C_{F l}^{1}\right)$ & $3581 \times 10^{3} €$ \\
Price per unit capacity of investment $\left(V_{F l}^{\mathrm{In}}\right)$ & $350 \times 10^{3} €$ \\
Price per unit capacity of disinvestment $\left(V_{F l}^{\text {OUT }}\right)$ & $437 \times 10^{3} €$ \\
Investment Fraction $\left(I_{F l}^{+}\right)$ & 0.125 \\
Dis-investment Fraction $\left(I_{F l}^{-}\right)$ & 0.125 \\
Lag in investment decision $\left(L A G_{F l}\right)$ & 1 year \\
Number of year for averaging profit $(L G T)$ & 2 years \\
Discount rate $(r)$ & $5 \%$ \\
Expected lifetime $(L T)$ & 20 years \\
Catch value fraction $(\mathrm{CVF})$ & 0.29 \\
Catch weight fraction $(\mathrm{CCF})$ & 0.61 \\
Fleet Segment Share $(\mathrm{FSS})$ & 0.08 \\
\hline
\end{tabular}

\subsection{Data}

The start year in the simulation is set to 2003, i.e. the year before the cod recovery plan was set into force. The cod stock was initialised in 2003 using cohort and catch data presented by the ICES Working Group on the Assessment of Demersal Stocks in the North Sea and Skagerrak (ICES 2006). It is assumed that the natural mortality and the maturity rate of the stock are constant throughout the simulation period and equal to the values also given in ICES (2006). Table 1 presents the stock and catch data used to initialise the stock.

The Danish seine fleet operating in the North Sea is initialised using data from the Annual Economic Report on the Economic Performance of Selected European Fishing Fleets (AER 2004) and from the Danish Fishery Statistics. A summary of the data used to initialise the fleet in 2003 is given in Table 2.

The maximum number of sea days in a year for a Danish Seine vessel is set to $12 \times 22=264$ days according to the CFP effort regulation. The maximum number of vessels allowed in the fleet is set to two times the number of vessels in 2003, i.e. to 74 vessels, thus allowing the fleet to expand if there is positive profit. The minimum number of vessels is set to 1 , thus 


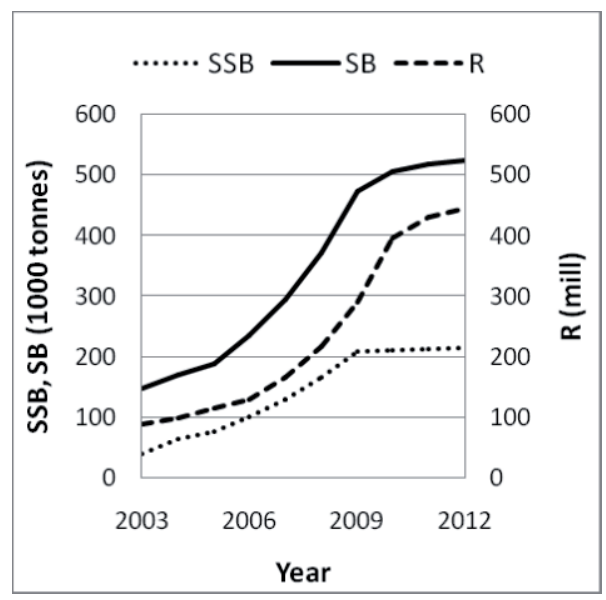

Fig. 2. Development of spawning stock biomass (SSB), stock biomass $(\mathrm{SB})$ and recruitment $(\mathrm{R})$ during the simulation period.

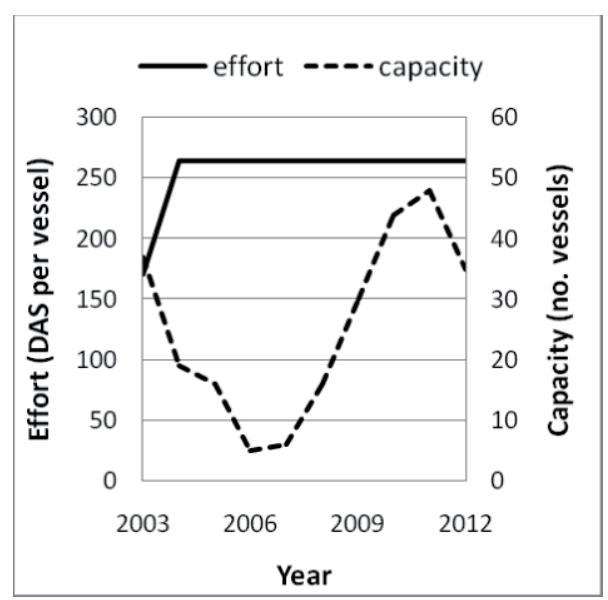

Fig. 3. Effort (number of sea days per vessel) and capacity (number of vessels) during the simulation period for the fleet of Danish seiners operating in the North Sea.

allowing the fleet to recover after a period of severe negative profits $^{4}$.

Finally, the Danish share (relative stability) of the North Sea cod TAC is equal to $C S_{D K}^{\mathrm{Cod}}=20.45 \%$, and the exponents used in the CPUE evaluations have been set to $\beta_{F l}=0.8$ and $\gamma_{F l}=1$.

\section{Simulation results}

The model has been run from the initialisation year 2003 until 2012 which has proven to be a more than sufficient time period for the stock to recover. When running the simulation with the above parameters, the stock and recruitment follow the paths shown in Figure 2. It can be seen that SSB increases above the precautionary limit of $150000 \mathrm{t}$ and

\footnotetext{
${ }^{4}$ If the minimum number of vessels is set to zero, no earnings will be created for the fleet in the model, and the fleet will thus never be allowed to recover/reinvest.
}

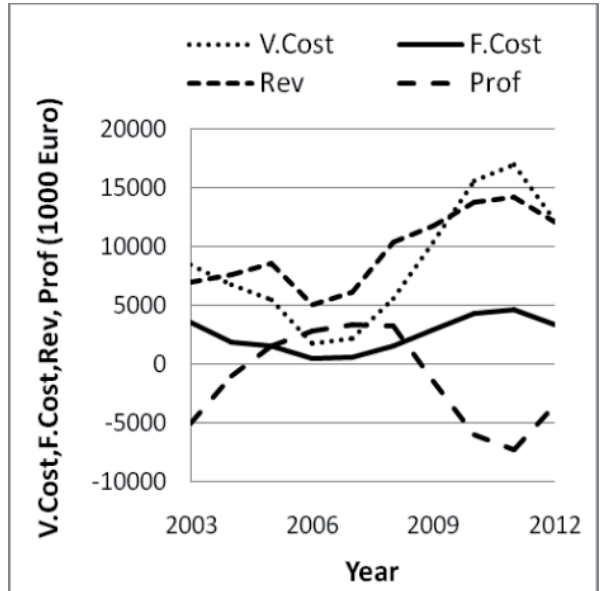

Fig. 4. Variable and fixed costs (V. Cost, F. Cost), total revenues (Rev) and total profits (Prof) during the simulation period for the fleet of Danish seiners operating in the North Sea.

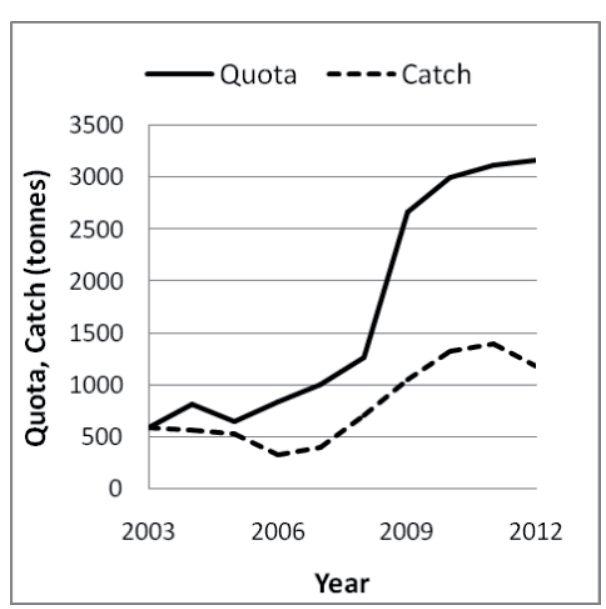

Fig. 5. Yearly cod quotas and catches during the simulation period for the fleet of Danish seiners operating in the North Sea.

stabilises around $210000 \mathrm{t}$. The recovery of the cod stock to above the precautionary limit takes around 6 years.

Figure 3 shows the development in the fleet effort (number of sea days per vessel) and the capacity (number of vessels). Figure 4 shows the economic indicators for the fleet, and Figure 5 shows the fleet quotas and catches during the simulation period.

The fleet capacity decreases steeply throughout most of the recovery period (2004 to $\sim 2008$ ), but then starts to rise as the stock recovers (Fig. 3). The cause of the initial fall in capacity is the negative profit (Fig. 4) of the fleet at the beginning of the simulation period, which, given the lag in investment (cf. Eq. (1)), is followed by a period of disinvestment. This unfavourable economic situation for the fleet at the beginning of the period is caused by a combination of low quotas and severe overcapacity to which disinvestment is a natural reaction. It must, however, be kept in mind that it is probably not realistic for the fleet to disinvest down to only $\sim 5$ vessels, as many vessels will probably choose to stay in the fishery despite the negative earnings. 
Figure 3 also shows that the effort limit of 264 days per vessel is reached each year throughout the management period (2004-2012), meaning that the fleet is not able to take the full cod quota in any of the simulation years. The fleets' catch and quota are shown in Figure 5 where it is seen that the fraction, which the fleet is able to take of its quota, decreases during the simulation period. The reason for this is to be found in the decreasing capacity of the fleet. It has been shown by additional simulations, that if the fleet had not been allowed to disinvest, it would have been able to take larger parts of the yearly quota, but with negative earnings each year due to the overcapacity.

\section{Discussion and conclusion}

The model and the case study presented above is naturally a simplification of the actual dynamics between fishing biology, management plans and economy. During the model simulations it became apparent that the model is extremely sensitive to the initialisation parameters. It is, however, still the belief of the authors that the model gives a plausible indication of the response of a given fleet to the changing quota situation during a recovery scheme. It is especially interesting to follow the response of the fleet to the additional effort limitation on fishing days. This is the limiting factor throughout the simulation period for the presented case study. The simulations thus indicate that it may be difficult for fishing fleets to take their full quotas if additional effort limitations are set into force. This is obviously an advantage from a biological point of view, as it will allow the threatened stocks to recover faster, but it is quite a disadvantage for the involved fleets.

Therefore, even though the model is a simplification of the real world, it still gives a very detailed account of the possible response of a fishery to combined effort and quota regulations. As such, the value of this new model is particularly to be found in the fact that it provides stakeholders with additional socio-economic information about the possible effects of new management regimes including effort regulation. It should be clear that the model can be extended to more fleets and more species, and that the model as such is a valuable addition to the ongoing research in the evaluation of management schemes.

\section{References}

AER (Annual Economic Report), 2004, Economic Performance of Selected European Fishing Fleets - Annual Report 2004. Concerted Action (Q5CA-2001-01502).

Bjørndal T., Conrad J.M., 1987, Capital Dynamics in the North Sea Herring Fishery. Mar. Resour. Econ. 4, 63-74.
Danielsson A., Stefansson G., Baldursson F.M., Thorarinsson K., 1997, Utilization of the Icelandic cod stock in a multispecies context. Mar. Resour. Econ. 12, 329-344.

Da-Rocha J.M., Gutiérrez M.J., 2004, The evaluation of fisheries management: a dynamic stochastic approach. University of the Basque Country - Dep. Foundations of Economic Analysis II Se. DFAEII Working Papers $N^{\circ} 200304$.

Da-Rocha J.M., Gutiérrez M.J., 2006, the optimality of the common fisheries policy: the northern stock of hake. Spain Econ. Rev. 8, $1-21$.

EC, 2004, Council Regulation (EC) No 423/2004 of 26 February 2004 establishing measures for the recovery of cod stocks. Off. J. Eur. Union 9.3.2004, 8-11.

EC, 2002, Council Regulation (EC) No 2371/2002 of 20. December 2002 on the conservation and sustainable exploitation of fisheries resources under the Common Fisheries Policy. Off. J. Eur. Communities L358, 59-80.

Eide A., Skjold F., Olsen F., Flaaten O., 2003, Harvest functions: The Norwegian bottom trawl cod fisheries. Mar. Resour. Econ. 18, 81-94.

EFIMAS, 2007, http://www.efimas.org/ (the EFIMAS website).

FLR 2007, http://flr-project.org/doku.php (the FLR website).

Garza-Gil M.D., Varela-Lafuente M.M., Suris-Regueiro J.C., 2003, European hake fishery bioeconomic management (southern stock) applying en effort tax. Fish. Res. 60, 199-206.

Garza-Gil, M.D., Varela-Lafuente M.M., Suris-Regueiro J.C., 2006, Gestión de una pesquieria mediante impuestos: la pesqueria de merluza europa. Hacienda Pública Esp./Rev. Econ. Pública 177(2), 9-23.

Hoff A., Frost H., 2008, Modelling combined harvest and effort regulations: the case of the Dutch beam trawl fishery for plaice and sole in the North Sea. ICES J. Mar. Sci. doi: 10.1093/icesjms/fsn057.

Hoff A., Frost H., Economic response to harvest and effort control in fishery. University of Copenhagen, Institute of Food and Resource Economics, Report $\mathrm{N}^{\circ} 185$.

ICES (Int. Counc. Explor. Sea), 2005, Report of the ICES Advisory Committee on Fishery Management, Advisory Committee on the Marine Environment and Advisory Committee on Ecosystems. Vol. 6, Advice - North Sea.

ICES, 2006, Report of the Working Group on the Assessment of Demersal Stocks in the North Sea and Skagerrak (WGNSSK). ICES WGNSSK report 2006, ACFM:35.

Kell L.T., Mosqueira I., Grosjean P., Fromentin J.-M., Garcia D., Hillary R., Jardim E., Pastoors M., Poos J.J., Scott F., Scott R.D., 2007, FLR: an open-source framework for the evaluation and development of management strategies. ICES J. Mar. Sci. 64, 640646.

Skjold F., Eide A., Flaaten O., 1996, Production functions of the Norwegian bottom trawl fisheries of cod in the Barents Sea. C.M. 1996/P3. Int. Counc. Explor. Sea, Copenhagen.

Sparre P., 1998, Introduction to Tropical Fish Stock Assessment Part 1: Manual. FAO Fish. Tech. Pap., 306/1. 